\title{
DAMPAK KUALITAS PELAYANAN TERHADAP KEPUASAN PASIEN \\ RUMAH SAKIT (Analisis Pengukuran Kinerja NonKeuangan)
}

\author{
DIAN PURNAMA SARI \\ Universitas Katolik Widya Mandala Surabaya \\ ERWIN SARASWATI \\ Jurusan Akuntansi Fakultas Ekonomi dan Bisnis \\ Universitas Brawijaya
}

\begin{abstract}
Performance measurement in hospitals is difficult to do because the human resources did much in the operational activities. This study tried to analyze patient satisfaction as one of the non-financial measurement process quality of services performed by doctors, nurses and pharmacy staff. Results of this study showed that the quality of the service process by doctors, nurses and successfully treatment significantly influence patient satisfaction. This indicates that the quality of the service process by doctors, nurses and successfully treatment can be measured through patient satisfaction. Quality of the service process by pharmacy staff and ease adminitratif no significant effect on patient satisfaction. That is, there is the quality of the service process by pharmacy staff and ease adminitratif should be measured through the measurement of non-financial sharing.
\end{abstract}

Keywords: Patient Satisfaction, Non-Financial Measurement, Hospital, Quality of Service

\section{Latar Belakang}

Pendidikan, kesehatan dan kestabilan ekonomi merupakan ukuran keberhasilan kinerja suatu negara (Europian Central Bank, 2003; Afonso, Schuknecht dan Tanzi, 2006; Therkildsen, 2001), sedangkan kesehatan merupakan salah satu kebutuhan dasar manusia. Oleh karena itu, pemerintah, baik pusat maupun daerah, harus melaksanakan usaha pelayanan kesehatan yang baik bagi seluruh masyarakat melalui rumah sakit. Pelayanan rumah sakit merupakan salah satu faktor kunci yang dapat menentukan kinerja rumah sakit (Chakraborty dan Majumdar, 2011). Harus diakui bahwa pengukuran kinerja rumah sakit tidaklah mudah, seperti pada umumya pengukuran kinerja di sektor publik. Dalam hal ini diperlukan indikator kinerja yang memudahkan untuk mengukur kinerja (Mahmudi, 2007), sehingga pengukuran kinerja rumah sakit memerlukan indikator yang tepat (Peursem, Pratt dan Lawrence, 1995) agar dapat tercapai tujuan yang diinginkan. Hal ini berarti penting untuk menentukan indikator kualitas pelayanan rumah sakit.

Pemerintah Indonesia telah berusaha untuk meningkatkan pelayanan kesehatan bagi masyarakat dengan menyelenggarakan Jaminan Kesehatan Nasional (JKN). JKN masih menjadi topik hangat di Indonesia. Berbagai kebijakan Badan Penyelenggara Jaminan Sosial 
(BPJS) Kesehatan selaku pengelola JKN di Indonesia masih menuai pro dan kontra. Kebijakan rujukan berjenjang (yang berlaku sejak 22 September 2018), kebijakan pendidikan Dokter Layanan Primer (DLP), Pengenaan urun biaya (Permenkes nomor 51 tahun 2018), penerapan e-Catalog yang "menyamakan" harga obat serta kebijakan-kebijakan lain. Beberapa di antaranya belum berjalan dengan baik, namun kebijakan BPJS Kesehatan tetap berjalan. Para pasien, selaku "konsumen” dari BPJS Kesehatan dan layanan kesehatan di Indonesia seringkali menjadi “korban” kebijakan BPJS Kesehatan. Tetapi, jangn lupa, rumah sakit sebagai pelayanan kesehatan juga seringkali tidak setuju dengan kebijakan-kebijakan BPJS Kesehatan. Kinerja rumah sakit pemerintah belum sepenuhnya efektif, terbukti hasil pemeriksaan BPK pada tahun 2010 menyimpulkan bahwa manajemen rumah sakit belum efektif dalam mengelola pelayanan rawat inap, rawat jalan dan farmasi, sehingga belum optimal dalam menunjang pelayanan kesehatan yang prima (BPK-RI, 2011, p. 77). Kemungkinan disebabkan pengukuran kinerja yang kurang tepat, terutama dalam hal kualitas pelayanan.

Proses pelayanan merupakan hal yang pokok dalam kegiatan operasional sebuah rumah sakit dan dokter adalah sentral layanan kesehatan, bukan rumah sakit ataupun klinik (Jacobs, Marcon \& Witt, 2004). Disamping itu, perawat dan farmasi memiliki peranan penting dalam menentukan kualitas layanan kesehatan dalam sebuah rumah sakit. Ketiga jenis staf inilah yang menjadi inti pokok dalam proses pelayanan di rumah sakit, karena melayani pasien secara langsung dalam hubungannya dengan kesembuhan sang pasien. Fokus proses pelayanan pada kepuasan pasien dan interaksi medis, sosial dan psikologis antara pasien dan praktisi rumah sakit. Beberapa peneliti menyatakan bahwa kepuasan pasien tidak hanya pada kualitas pelayanan, tetapi juga niat dari pasien untuk menggunakan jasa rumah sakit (Padman, Rajendran dan Lokachari, 2010). Hal ini merupakan konsep keterkaitan antara komunikasi dan kegiatan yang berlangsung antara manusia, dan tidak dapat dinyatakan dalam istilah mekanistik. Oleh karena itu, mengukur kinerja rumah sakit dibutuhkan pengukuran non-financial yang berkaitan dengan kepuasan pasien. Ittner \& Larcker (1998) menemukan bahwa sebenarnya dalam uji tingkat individu konsumen, kepuasan pelanggan merupakan indikator utama untuk mengukur kinerja akuntansi. 
Hasil penelitian menyatakan bahwa kualitas pelayanan ditentukan oleh kepuasan pelanggan (Badri, Attia, \& Ustadi, 2008; Chakraborty \& Majumdar, 2011; Larsson \& WildeLarsson, 2010; Newman, Maylor, \& Chansarkar, 2011; Padma et al., 2011; dan Zineldir, 2006), sedangkan hasil penelitian yang dilakukan di berbagai rumah sakit yang berbeda, baik jenis (rumah sakit pemerintah atau rumah sakit privat), pengukuran dari sudut pandang yang berbeda, ataupun negara yang berbeda, memiliki hasil yang kurang lebih sama, yaitu terdapat hubungan antara kualitas pelayanan industri layanan kesehatan terhadap kepuasan pelanggan. Di Indonesia, penelitian mengenai pengukuran kinerja untuk industri kesehatan lebih banyak menggunakan balanced scorecard (Gowon, 2004), sepengetahuan peneliti belum banyak yang mencoba menfokuskan diri pengukuran kualitas proses pelayanan yang merupakan kegiatan sentral dalam sebuah rumah sakit. Penelitian ini menguji kualitas proses pelayanan di rumah sakit yang lebih banyak didasarkan pada perilaku manusia sebagai sumber dayanya yang diukur menggunakan pengukuran kinerja non-finansial, yaitu kepuasan pasien. Kontribusi penelitian diharapkan dapat mengembangkan akuntansi manajemen dalam hal pengukuran kinerja non-keuangan di rumah sakit.

\section{Tinjauan Teori dan Pengembangan Hipotesa}

Padma, et al. (2010) berupaya untuk mengkonseptualkan kualitas pelayanan rumah sakit dengan komponen perspektif pasien dan penjaganya dan menganalisis hubungan antara kualitas pelayanan dan kepuasan pelanggan. Kepuasan pelanggan diukur menggunakan 8 konstruk, yaitu infrastruktur, kualitas personal, proses perawatan klinis, prosedur administrative, langkah-langkah keselamatan, citra rumah sakit, tanggung jawab sosial dan kepercayaan terhadap rumah sakit. Hasil penelitian ini menunjukkan bahwa aspek pelayanan interpersonal adalah yang paling penting dalam memberikan kepuasan bagi pasien dan penjaganya.

Zineldir (2006) mengembangkan model 5Qs dengan 48 instrumen untuk mengukur kepuasan pelanggan, yaitu kualitas objek, kualitas proses, kualitas infrastruktur, kualitas hubungan tindakan dan kualitas atmosfer. Penelitian ini dilakukan di tiga rumah sakit di Mesir dan Yordania. Hasil penelitian ini menunjukkan bahwa cara untuk meningkatkan kepuasan pasien di rumah sakit pertama adalah untuk mempengaruhi pada dua dimensi kualitas total: kualitas infrastruktur dan kualitas atmosfer, pada rumah sakit kedua 
implementasi dalam infrastruktur dan suasana di rumah sakit dapat meningkatkan kepuasan pasien. Di sisi lain, di rumah sakit ketiga, pasien sebagian besar puas dengan kualitas proses, kualitas infrastruktur dan kualitas interaksi.

Rumah sakit adalah suatu organisasi yang melalui tenaga medis profesional yang terorganisasi, serta sarana kedokteran yang permanen menyelenggarakan pelayanan kedokteran, asuhan keperawatan yang berkesinambungan, diagnosis, serta pengobatan penyakit yang diderita pasien (BPK-RI, 2011, p. 77). Rumah sakit merupakan organisasi yang mempunyai misi ganda, yaitu misi sosial yang lebih menekankan pada unsur sosial dan nilai pelayanan kesehatan. Di sisi lain, rumah sakit harus efisien untuk dapat tetap beroperasi dan meningkatkan pelayanan. Oleh karenanya, pengukuran kinerja keuangan dan nonkeuangan menjadi hal yang penting.

Peursem et al. (1995) mengungkapkan bahwa pengukuran kinerja dalam manajemen di bidang kesehatan merupakan tugas yang menantang. Kemungkinan hal ini berkaitan dengan misi ganda rumah sakit, sehingga pengukuran kinerja merupakan suatu hal yang sulit dilakukan. Pengukuran kinerja kinerja di bidang kesehatan dapat digambarkan sebagai berikut:

\section{Gambar 1}

\section{Metode Pengukuran Kinerja di Bidang Kesehatan}

\section{Gambar 1 dapat dilihat dalam Lampiran 1}

Prespektif akuntabilitas berkaitan dengan pertanggungjawaban sosial, sedangkan prespektif pengukuran merupakan hal yang sulit, karena harus dibedakan mengukur (measure) dan pengukuran (measurement). Dalam sektor publik pengukuran kinerja lebih ditekankan pada value for money (ekonomis, efisiensi dan efektivitas). Ketiganya berkaitan dengan input, output dan outcome.

Pengukuran ekonomis dan efisiensi relatif lebih mudah, karena menghubungkan input dan output yang secara relatif lebih mudah diukur dari pada outcome, dalam hal ini berkaitan dengan efektivitas. Pada layanan rumah sakit outcome lebih dekat dengan kualitas 
Dampak Kualitas Pelayanan Terhadap Kepusasn Pasien Rumah Sakit (Analisis Pengukuran Kinerja

pelayanan rumah sakit (Peursem, et al.,1995), sehingga prespektif pengukuran adalah pengukuran non-keuangan. Kepuasan pelanggan, dalam hal ini pasien merupakan indikator pengukuran non-keuangan.

Kepuasan merupakan hasil kesimpulan seseorang tentang perbandingan antara pelayanan yang diharapkan dengan hasil yang nyata-nyata diperolehnya. Oliver (1989) dalam Padma, et al. (2010) mendefinisikan kepuasan sebagai respon evaluatif, afektif, atau emosional. Pelanggan dapat mengevaluasi objek hanya setelah mereka menmahami objek. Oleh karena itu, kepuasan adalah evaluasi pasca-pembelian produk atau jasa yang sesuai harapan sebelum pembelian. Kepuasan tergantung pada kemampuan perusahaan untuk memenuhi hukum pelanggan dan harapan dan tidak peduli seberapa baik layanan, pelanggan akan terus mengharapkan layanan yang lebih baik (Padma, et al., 2010).

Tujuan penelitian ini adalah untuk ingin memberikan bukti empiris hubungan pengukuran non-finansial dengan indikator kualitas proses pelayanan, dengan kepuasan pasien dalam sebuah rumah sakit. Kualitas proses pelayanan dibagi menjadi dua divisi yang angsung bersentuhan dengan pasien, yaitu divisi jasa (meliputi dokter dan perawat), serta divisi dagang (yaitu staf farmasi). Secara lebih jelas, model penelitian ini digambarkan sebagai berikut:

\section{Gambar 2}

Model Penelitian

\section{Gambar 2 dapat dilihat dalam Lampiran 1}

Sesuai dengan model penelitian dalam Gambar 2, maka hipotesis yang diajukan dalam penelitian ini adalah:

H1: Kualitas proses pelayanan dokter berpengaruh signifikan kepada kepuasan pasien

H2: Kualitas proses pelayanan perawat berpengaruh signifikan kepada kepuasan pasien

H3: Kualitas proses pelayanan staf farmasi berpengaruh signifikan kepada kepuasan pasien 
Dampak Kualitas Pelayanan Terhadap Kepusasn Pasien Rumah Sakit (Analisis Pengukuran Kinerja

H4: Kemudahan administratif proses pelayanan berpengaruh signifikankepada kepuasan pasien

H5: Keberhasilan pengobatan berpengaruh signifikan kepada kepuasan pasien

\section{Model Penelitian}

\section{Sample}

Penelitian ini dilakukan di sebuah Rumah Sakit Umum Daerah milik pemerintah di Jawa Timur. Rumah sakit “SA” merupakan rumah sakit pendidikan utama dengan akreditasi A. Proses pengumpulan data dalam penelitian ini dilakukan dengan survei. Kuisioner dibagikan kepada pasien ataupun keluarga pasien, baik rawat inap maupun rawat jalan untuk mengukur tingkat kepuasan pasien. Devisi yang diamati adalah divisi jasa dan divisi dagang, untuk mengukur kualitas pelayanan. Divisi jasa meliputi dokter dan perawaat, sedangkan divisi dagang meliputi apoteker dan staf farmasi yang secara langsung berinteraksi dengan pasien. Skala instrumen penelitian dari angka 1 hingga 5, yang menunjukkan sangat tidak puas (1) hingga sangat puas (5). Kuesioner yang kembali dan dapat diolah adalah sebanyak 44.

\section{Instrumen Penelitian}

Sesuai dengan topik penelitian ini, maka instrumen penelitian ini disesuaikan dengan variabel penelitian. Kualitas proses pelayanan, sebagai variabel independen, dibagi menjadi dua divisi utama yaitu, divisi jasa, oleh dokter dan perawat, serta divisi dagang, oleh staf farmasi. Kepuasan pelanggan, sebagai variabel dependen, diukur melalui kepuasan pasien. Instrumen penelitian ini diadaptasi dari penelitian Padma, et al. (2010) dan Zineldir (2006). Variabel kualitas proses pelayanan untuk menilai kepuasan pasien meliputi: (1)Kualitas proses pelayanan oleh dokter dengan indikator (a) profesionalisme, kompetensi, dan keahlian dokter; (b) kualitas personal dokter (ramah dan peduli terhadap kebutuhan pasien); (c) mampu menghadapi keluhan pasien; (d) interaksi dengan dokter spesialis bila dibutuhkan; (e) kepercayaan pasien kepada dokter. Variavel kualitas proses pelayanan oleh perawat meliputi (a) kompetensi dan keahlian perawat; (b) kualitas personal perawat (sopan dan perhatian); (c) ketrampilan dengan tanggap terhadap kebutuhan pasien; (d) mampu menghadapi keluhan 
pasien. Variabel kualitas proses pelayanan oleh staf farmasi meliputi (a) kesopanan saat menghadapi pasien; (b) kualitas personal staf farmasi ( peduli dan perhatian); (c) cekatan, baik dan ramah dalam menyediakan obat bagi pasien; (d) proses pengambilan obat di apotik atau tempat pengambilan obat.

Variabel kemudahan administratif proses pelayanan meliputi (a) jadwal pelayanan yang sesuai kebutuhan pasien; (b) kecepatan dan ketepatan proses pelayanan; (c) waktu tunggu giliran diperiksa; (d) kemudahan dalam berkonsultasi dengan dokter; (e) bantuan untuk perawatan tambahan bila diperlukan. Variabel keberhasilan pengobatan meliputi (a) keberhasilan pengobatan; (b) kualitas saran dan petunjuk medis saat selesai pengobatan; (c) kebenaran diagnosis dan kondisi pasien; (d) penjelasan mengenai prosedur pengobatan dan hasilnya; (e) informasi yang jelas mengenai tes medis dan kondisi kesehatan pasien; (f) ketepatan penangan komplikasi yang tak terduga

\section{Hasil Penelitian}

Data yang diperoleh akan dianalisis dengan menggunakan Partial Least Square (PLS). Analisis PLS adalah teknik statistika multivariate yang melakukan pembandingan antara variabel dependen berganda dan variabel independen berganda (Jogiyanto \& Abdillah, 2009). Analisis PLS digunakan dalam penelitian ini karena dinilai merupakan alat analisis yang paling sesuai dengan penelitian ini dibandingkan alat statistik lainnya. PLS mampu menjadi metode analisis yang powerfull, karena dapat diterapkan pada semua skala data, tidak banyak membutuhkan asumsi dan ukuran sampel tidak harus besar (Wiyono, 2011).

\section{Statistik Deskriptif}

Penelitian ini dilakukan dengan menggunakan metode survei dengan pengisian kuisioner oleh pasien rumah sakit "SA" dan kuisioner kembali yang dapat diolah adalah sebanyak 44 kuisioner. Deskripsi responden disajikan dalam Tabel 1:

Tabel 1

Deskripsi Responden

\section{Tabel 1 dapat dilihat dalam lampiran 2}


Berdasarkan deskripsi Tabel 1, maka dapat diketahui bahwa mayoritas responden berjenis kelamin laki-laki sebesar 68\%. Usia responden didominasi usia 51-70 tahun, yaitu 52.3\%, usia 31-50 tahun berada di urutan kedua dengan persentase 31.8\%. Sisanya ada di usia di atas 70 tahun dengan 9.08\%, serta usia di bawah 30 tahun sebanyak 6,82\%. Untuk jenis perawatan didominasi oleh pasien rawat jalan dengan persentase $65.1 \%$ dan pasien rawat inap hanya sebesar 34.9\%. Hal ini berarti sebagian besar responden merupakan pasien dengan layanan rawat jalan.

\section{Uji Indikator}

Sebelum data dianalisis, indikator yang digunakan dalam penelitian ini harus diuji terlebih dahulu. Uji indikator digunakan, agar mengetahui validitas dan reabilitas instrumen yang digunakan dalam penelitian ini. Dengan menggunakan bantuan SmartPLS 2.0, maka hasil uji indikator disajikan dalam Tabel 2:

Tabel 2

Hasil Uji Indikator

\section{Tabel 2 dapat dilihat dalam Lampiran 3}

Tabel 2 menunjukkan bahwa instrumen yang digunakan valid dan realibel. Uji convergent validity menunjukkan bahwa masing-masing instrumen yang digunakan dalam penelitian ini bernilai di atas 0,50, sehingga dapat disimpulkan bahwa seluruh instrumen yang digunakan adalah valid. Demikian pula untuk setiap variabel, Average Variance Extracted (AVE), setiap variabel bernilai di atas 0,50, maka dapat dikatakan seluruh variabel adalah valid. Composite Reliability digunakan untuk mengetahui reabilitas variabel penelitian ini. Dengan nilai Composite Reliability di atas 0,70 maka seluruh variabel dalam penelitian ini dinyatakan realibel. 


\section{Uji Struktural}

Uji Struktural dapat dilihat da;am hasil algoritma PLS yang disajikan dalam gambar 3 berikut ini:

Gambar 3

Hasil Algoritma PLS

\section{Gambar 3 dapat dilihat dalam Lampiran 3}

Gambar 3 menunjukkan koefisien parameter antar variabel. Variabel kualitas proses pelayanan oleh dokter (KPD) memiliki pengaruh yang positif terhadap kepuasan pasien dengan besar koefisien 0,319. Variabel kualitas proses pelayanan oleh perawat (KPP) memiliki pengaruh yang positif terhadap kepuasan pasien dengan koefisien 0,576. Variabel kualitas proses pelayanan oleh staf farmasi (KPF) memiliki pengaruh yang negatif terhadap kepuasan pasien dengan koefisien 0,018. Variabel kemudahan administratif (KA) memiliki pengaruh yang negatif terhadap kepuasan pasien dengan koefisien 0,016. Variabel keberhasilan pengobatan (KPO) memiliki pengaruh yang positif terhadap kepuasan pasien dengan koefisien 0,166. Hasil tingkat signifikasi disajikan dalam Tabel 3 berikut ini:

Tabel 3

Hasil Inner Model T-Statistic

\section{Tabel 3 dapat dilihat dalam Lampiran 3}

Berdasarkan nilai T-Statistik dari Tabel 3, hubungan signifikan bila nilai T-Statistic di atas nilai 1,96 (Jogiyanto \& Abdillah, 2009). Variabel kualitas proses pelayanan oleh dokter memiliki pengrauh yang signifikan dengan kepuasan pasien dengan nilai 3.735511. Variabel kualitas proses pelayanan oleh perawat memiliki pengaruh yang signifikan terhadap kepuasan pasien dengan nilai 8.381293. Variabel keberhasilan pengobatan memiliki pengaruh yang signifikan terhadap kepuasan pasien dengan nilai 2.16899. Variabel kualitas proses pelayanan oleh staf farmasi tidak memiliki pengaruh yang signifikan terhadap kepuasan pasien (dengan nilai 0.342556) dan variabel kemudahan administratif juga tidak memiliki pengaruh yang 
signifikan terhadap kepuasan pasien (dengan nilai 0,204306). Hasil ini menunjukkan bahwa Hipotesis 1, Hipotesis 2 dan Hipotesis 5 didukung, sedangkan Hipotesis 3 dan Hipotesis 4 ditolak. Secara keseluruhan model dalam penelitian ini menunjukkan bahwa variabel kepuasan pelanggan dipengaruhi oleh variabel-variabel dependen sebesar 86,7\% (dengan nilai R Square 0.866983 ) sisanya sebesar 13,3\% dipengaruhi oleh faktor lain yang tidak terdapat dalam model.

\section{Pembahasan}

Hasil uji statistik menunjukkan bahwa hipotesis 1 didukung, artinya kualitas proses pelayanan oleh dokter berpengaruh signifikan terhadap kepuasan pasien secara positif. Semakin dokter yang melayani pasien berkualitas, maka kepuasan pasien akan meningkat. Hasil ini sesuai dengan penelitian Jacobs, et al. (2004) yang mengungkapkan dokter adalah tokoh sentral dalam pelayanan di rumah sakit. Hipotesis 2 ditemukan kualitas proses pelayanan oleh perawat berpengaruh signifikan terhadap kepuasan pasien secara positif. Artinya, semakin perawat yang melayani pasien berkualitas, maka kepuasan pasien juga akan meningkat. Hal in mungkin sejalan dengan proses pelayanan oleh dokter yang selalu didampingi oleh perawat dan tentu saja berhubungan langsung dengan pasien, konsisten dengan penelitian Newman, et al. (2001) yang menyimpulkan bahwa perawat yang puas dengan pekerjaannya berdampak pada kepuasan pasien. Hasil ini menunjukkan bahwa proses pelayanan oleh perawat dapat diukur melalui kepuasan pasien. Hipotesis 5 didukung, keberhasilan pengobatan berpengaruh signifikan terhadap kepuasan pasien secara positif. Artinya, apabila pasien merasa pengobatan yang diperolehnya di rumah sakit berhasil, maka pasien akan merasa puas. Keberhasilan pengobatan memang relatif, di mana pasien hanya mengungkapkan apa yang dirasakannya saat itu. Namun, hasil penelitian ini menunjukkan bahwa kepuasan pasien dapat menjadi salah satu cara untuk mengukur keberhasilan pengobatan di rumah sakit.

Hipotesis 3 ditolak, artinya kualitas proses pelayanan oleh staf farmasi tidak berpengaruh secara signifikan terhadap kepuasan pasien. Kondisi ini mungkin dipengaruhi bahwa pasien seringkali tidak berhubungan langsung dengan staf farmasi. Saat pasien menjalani rawat inap, obat-obatan seringkali langsung diberikan oleh perawat di ruangan. 
Pasien rawat inap tidak langsung berhubungan staf farmasi. Pasien rawat jalan pun mungkin mengalami hal yang sama. Biasanya, yang berhubungan dengan pengambilan obat untuk sang pasien adalah keluarga atau teman yang menemani si pasien. Oleh karena itu, untuk mengukur kepuasan Padma, et al. (2010) tidak hanya menggunakan responden si pasien, tetapi juga teman yang menemani si pasien. Hasil ini menunjukkan bahwa kualitas proses pelayanan staf farmasi tidak dapat diiukur menggunakan kepuasan pasien. Mungkin dapat dipertimbangkan untuk mengukur kualitas proses pelayanan staf farmasi dengan menggunakan responden teman yang menemani si pasien (seperti yang dilakukan oleh Padma, et al., 2010).

Hipotesis 4 juga ditolak, artinya kemudahan administratif tidak berpengaruh signifikan terhadap kepuasan pasien. Kemudahan administratif, yang meliputi waktu tunggu, kecepatan dan jadwal pelayanan, ternyata tidak berpengaruh kepada kepuasan pasien. Hal ini mungkin disebabkan rumah sakit yang menjadi objek penelitian adalah rumah sakit umum daerah milik pemerintah yang banyak menerima pasien rujukan dari berbagai daerah, serta hamper semua pasien adalah pasien JKN yang mau menerima kondisi tersebut. Pasien tidak terlalu banyak menuntut kemudahan secara adminitratif, tetapi lebih kepada proses pelayanan kesehatan yang dibutuhkannya. Hasil penelitian ini menunjukkan bahwa kualitas kemudahan administratif tidak dapat diukur melalui kepuasan pasien. Mungkin ada pengukuranpengukuran lain yang dapat dilakukan misalnya menggunakan jumlah pasien yang mampu ditangani oleh dokter setiap hari, ketepatan waktu pelayanan dan sebagainya.

Namun, variabel dependen mampu menjelaskan variabel independen sebesar 86.7\%. Artinya, model penelitian ini dapat dipertimbangkan untuk mengukur kualitas proses pelayanan rumah sakit dengan menggunakan kepuasan pelanggan sebagai pengukuran nonfinansial. Hasil penelitian ini juga menunjukkan bahwa sebuah rumah sakit harus memperhatikan kualitas proses pelayanan yang dilaksanakan oleh dokter serta perawat, karena merekalah tokoh sentral dari kepuasan pasien sebagai pelanggan rumah sakit.

Hal yang perlu diperhatikan adalah mayoritas pasien di rumah sakit adalah pasien JKN yang harus mengikuti aturan dari BPJS Kesehatan. Kita juga tidak menutup mata bahwa dengan banyaknya jumlah pasien, yang terkadang tidak sebanding dengan jumlah dokter maupun perawat, kualitas layanan yang diperoleh oleh pasien tidak maksimal. Pasien yang 
akan menerima resiko apabila terjadi kualitas layanan yang menurun. Salah satu sorotan tajam yang lain adalah masalah tunggakan pembayaran oleh manajemen BPJS kesehatan kepada rumah sakit-rumah sakit yang menjadi rujukan pasien BPJS kesehatan. Pada tahun 2015, BPJS defisit sekitar Rp 6 triliun dan diperkirakan pada tahun 2016 defisit Rp 9 triliun dan diperkirakan akan terus membengkak (Jawa Pos, 29 Desember 2016). Thabrany (2015) menyebutkan bahwa pengeluaran BPJS Kesehatan untuk layanan sudah di atas 100\%. Padahal dalam kaedah asuransi sosial, klaim rasio di atas 90\% sudah tidak ideal. Hal ini juga tentu berdampak pada kualitas layanan kepada pasien. Saran kepada BPJS Kesehatan selaku pengelola JKN adalah peningkatan kepuasan pasien melalui peningkatan kualitas dokter, perawat dan peralatan yang menunjang kesembuhan pasien, tidak hanya berkutat dengan rujukan berjenjang, e-catalogue ataupun program-program yang lain namun tidak relevan dengan visi awal BPJS Kesehatan, yaitu “Terwujudnya Jaminan Kesehatan (JKN-KIS) yang berkualitas dan berkesinambungan bagi seluruh Penduduk Indonesia pada tahun 2019 berlandaskan gotong royong yang berkeadilan melalui BPJS Kesehatan yang handal, unggul dan terpercaya”.

\section{Kesimpulan}

Penelitian ini menyimpulkan bahwa kualitas proses pelayanan dalam rumah sakit yang dapat diukur melalui kepuasan pasien meliputi kualitas proses pelayanan oleh dokter, kualitas proses pelayanan oleh perawat dan keberhasilan pengobatan. Kualitas proses pelayanan oleh staf farmasi dan kemudahan adminitratif tidak dapat diukur melalui kepuasan pasien. Kualitas proses pelayanan oleh staf farmasi disarankan untuk dikur melalui kepuasan orang yang menemani pasien berobat (seperti Padma, et al., 2010). Kemudahan administratif mungkin dapat diukur melalui jumlah pasien yang mampu ditangani dokter setiap harinya, ketepatan waktu layanan dan sebagainya.

Keterbatasan penelitian ini adalah waktu penyebaran kuisioner yang sangat pendek (5 hari), sehingga jumlah kuisioner yang kembali tidak banyak. Penyebaran kuisioner hanya dapat dilakukan secara acak, sehingga komposisi pasien rawat jalan dan pasien rawat inap tidaklah seimbang. Karena itu, pengembangan selanjutnya dapat dikembangkan metode survei dengan waktu yang lebih lama serta dapat dilakukan dengan purposive sampling agar kombinasi pasien rawat jalan dan rawat inap dapat lebih seimbang. 


\section{Daftar Pustaka}

Afonso, Antonio, Ludger Schuknecht dan Vito Tanzi. (2006). Public Sector Efficiency: Evidence from New EU Member States and Emerging Markets, (January). European Central Bank. Working Paper Series, No. 581.

Badri, M. A., Attia, S., \& Ustadi, A. M. (2008). Healthcare Quality and Moderators of Patient Satisfaction: Testing for Causality. International Journal of Health Care Quality Assurance, 22(4).

BPK-RI. (2011). Ikhtisar Hasil Pemeriksaan Semester II Tahun 2010.

BPK-RI. (2012). Ikhtisar Hasil Pemeriksaan Semester II Tahun 2011.

Chakraborty, R., \& Majumdar, A. (2011). Measuring Consumer Satisfaction in Healthcare Sector: The Applicability of Servqual. International Refereed Research Journal, 2(4).

European Central Bank. (2003). Public Sector Performances and Efficiency Indicators. Working Paper Series. No. 242.

Gowon, M. (2004). Analisis Pengukuran Kinerja Rumah Sakit DKT Jogja, Rumah Sakit PKU Muhammadiyah Jogja dan RSUD Sleman. Universitas Gadjah Mada, Yogyakarta.

Ittner, C. D., \& Larcker, D. F. (1998). Are Nonfinancial Measures Leading Indicators of Financial Performance? An Analysis of Customer Satisfaction. Journal of Accounting Research, 36.

Jacobs, K., Marcon, G., \& Witt, D. (2004). Cost and performance information for doctors: an international comparison. Management Accounting Research, 15(3), 337-354.

Jawa Pos. (2016). BPJS Kesehatan Berpotensi Bangkrut?. JawaPos.com, diunduh pada tanggal 25 Januari 2017

Larsson, G., \& Wilde-Larsson, B. (2010). Quality of Care and Patient Satisfaction: A New Theoretical and Methodological Approach. International Journal of Health Care Quality Assurance, 23(2), 228-247.

Mahmudi. (2007). Manajemen Kinerja Sektor Publik . Edisi Revisi. Yogyakarta: UPP STIM YKPN.

Newman, K., Maylor, U., \& Chansarkar, B. (2001). The Nurse Retention, Quality of Care and Patient Satisfaction Chain. International Journal of Health Care Quality Assurance, 14(2), 57-68. 
Padma, P., Rajendran, C., \& Lokachari, P. S. (2010). Service Quality and It's Impact on Customer Satisfaction in Indian Hospitals: Perpectives of Patients and Their Attendants. Benchmarking: An International Journal, 17(6), 807-841.

Peursem, K. A. V., Pratt, M. J., \& Lawrence, S. R. (1995). Health Management Performance: A Review of Measures and Indicators. Accounting, Auditing and Accountability Journal, 8(5), 34-70.

Thabrany, H. (2015). Agar BPJS Kesehatan Tidak Layu Sebelum Berkembang. Info BPJS Kesehatan: Media Internal Resmi BPJS Kesehatan Edisi XVII, Jakarta.

Therkildsen, Ole. (2001). Efficiency, Accountability and Implementation Public Sector Reform in East and Southern Africa. United Nations Research Institute for Social Development. Programme Paper No. 3. (February)

Wiyono, G. (2011). Merancang Penelitian Bisnis dengan Alat Analisis SPSS 17.0 \& SmartPLS 2.0. Yogyakarta: UPP STIM YKPN.

Zineldir, M. (2006). The Quality of Health Care and Patient Saisfaction: An Exploratory Investigation of the 5Qs model at some Egyptian and Jordanian Medical Clinics. International Journal of Health Care Quality Assurance, 19(1). 


\section{Lampiran 1}

Gambar 1

Metode Pengukuran Kinerja di Bidang Kesehatan

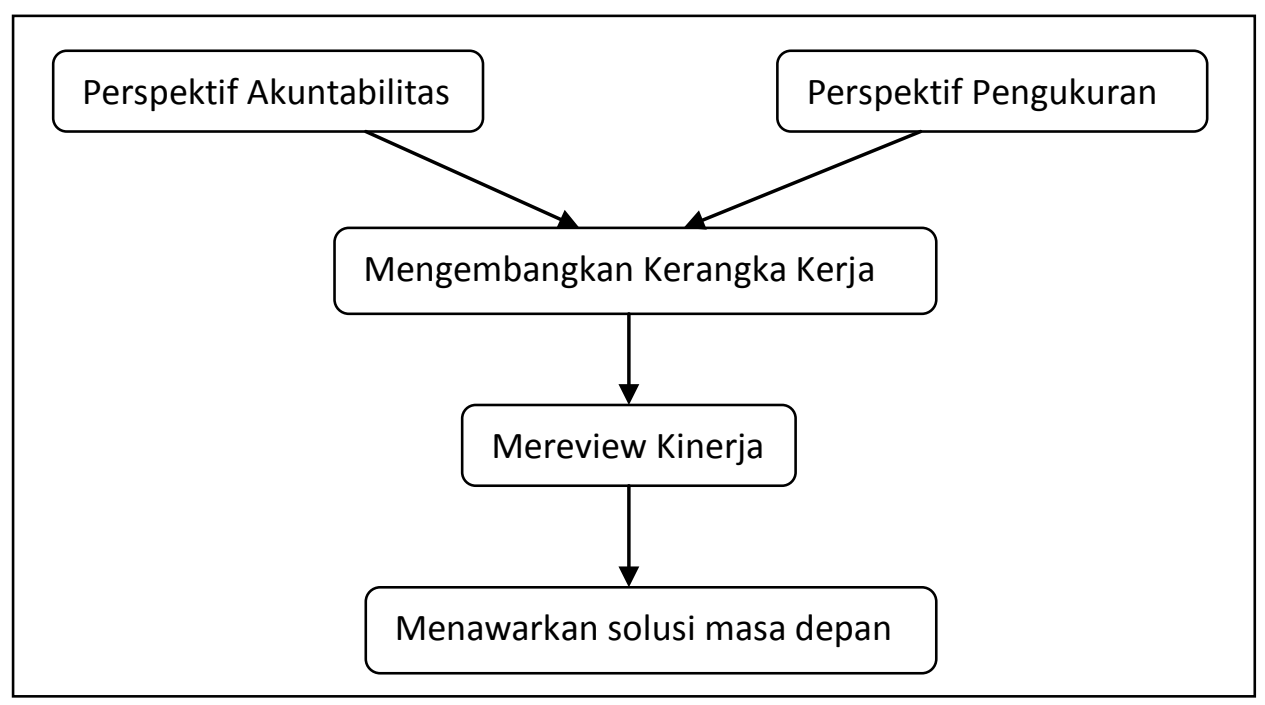

Sumber: Peursem, et al. (1995) 


\section{Gambar 2}

\section{Model Penelitian}

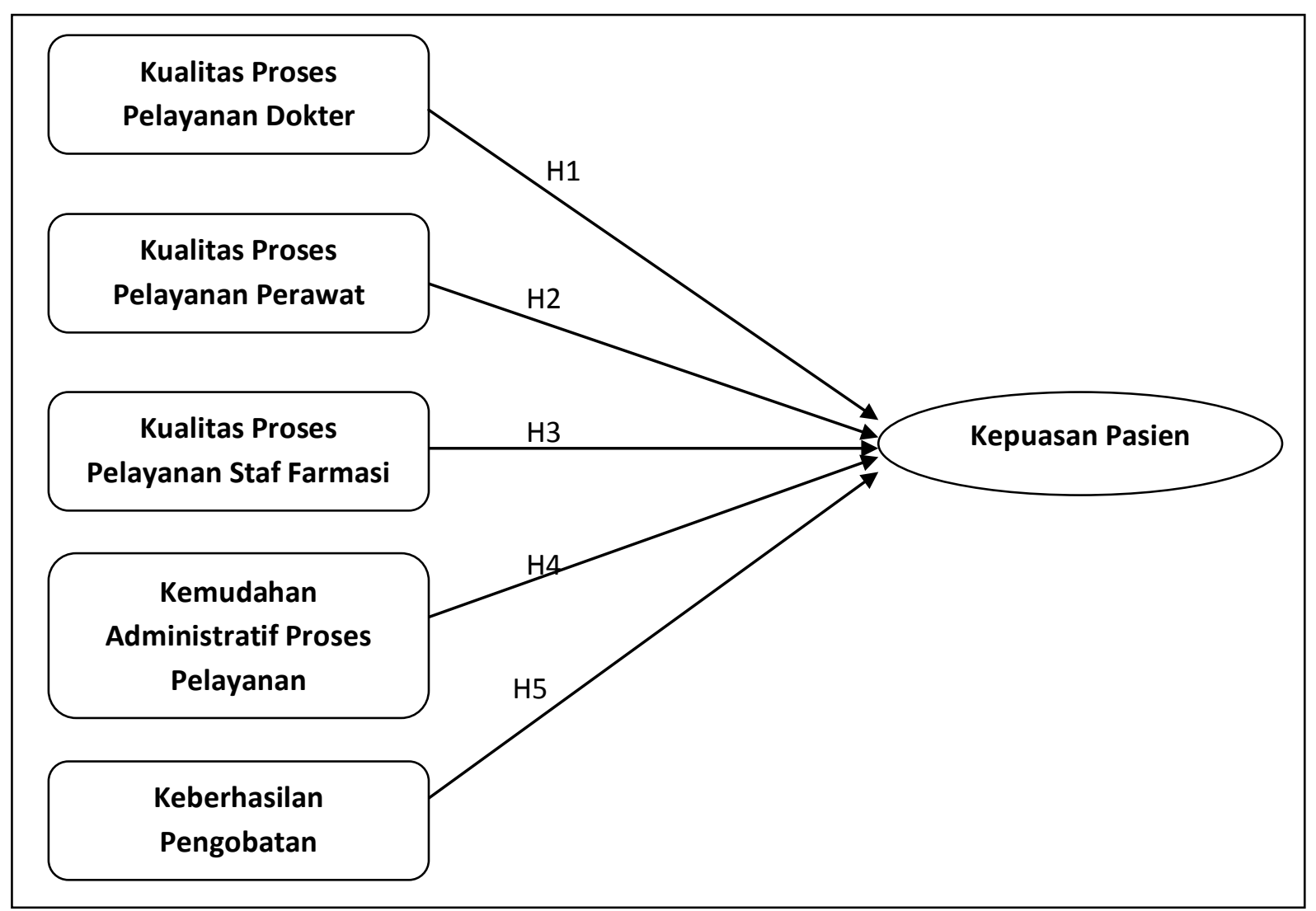

\section{Lampiran 2}

Tabel 1

Deskripsi Responden

\begin{tabular}{|l|l|l|l|l|l|}
\hline Deskripsi & \multicolumn{5}{|c|}{ Persentase } \\
\hline & \multicolumn{3}{|c|}{ Laki-Laki } & \multicolumn{1}{c|}{ Perempuan } & \multicolumn{1}{c|}{ Total } \\
\hline $\begin{array}{l}\text { Jenis } \\
\text { Kelamin }\end{array}$ & 30 & $68,2 \%$ & 14 & $31,8 \%$ & $44(100 \%)$ \\
\hline & $>30$ tahun & $31-50$ thn & $51-70$ thn & $>70$ & Total \\
\hline Usia & $3(6,82 \%)$ & $14(31,8 \%)$ & $23(52,3 \%)$ & $4(9,08 \%)$ & $44(100 \%)$ \\
\hline & Rawat Inap & $65,1 \%$ & 15 & $34,9 \%$ & $44(100 \%)$ \\
\hline $\begin{array}{l}\text { Jenis } \\
\text { Perawatan }\end{array}$ & 29 & Rawat Jalan & Total \\
\hline
\end{tabular}

Sumber: data primer diolah 


\section{Lampiran 3}

Tabel 2

Hasil Uji Indikator

\begin{tabular}{|c|c|c|c|}
\hline Validitas \& Reliabilitas & Indikator & Hasil Uji & Status \\
\hline \multirow{26}{*}{$\begin{array}{c}\text { Outer Loadings } \\
\text { (Convergent Validity) }\end{array}$} & KA 14 <- Kemudahan Admin & 0.807036 & Valid \\
\hline & KA15 <- Kemudahan Admin & 0.717789 & Valid \\
\hline & KA16 <- Kemudahan Admin & 0.695404 & Valid \\
\hline & KA24 <- Kemudahan Admin & 0.823075 & Valid \\
\hline & KA25 <- Kemudahan Admin & 0.814707 & Valid \\
\hline & KPD $5<-$ KPP Dokter & 0.838617 & Valid \\
\hline & KPD17 <- KPP Dokter & 0.681997 & Valid \\
\hline & KPD6 <- KPP Dokter & 0.927033 & Valid \\
\hline & KPD8 <- KPP Dokter & 0.933883 & Valid \\
\hline & KPF10 <- KPP Farmasi & 0.745715 & Valid \\
\hline & KPF11 <- KPP Farmasi & 0.804207 & Valid \\
\hline & KPF12 <- KPP Farmasi & 0.822831 & Valid \\
\hline & KPF9 <- KPP Farmasi & 0.835906 & Valid \\
\hline & KPO18 <- Keberhasilan Pengobatan & 0.841922 & Valid \\
\hline & KPO20 <- Keberhasilan Pengobatan & 0.832525 & Valid \\
\hline & KPO21 <- Keberhasilan Pengobatan & 0.741871 & Valid \\
\hline & KPO22 <- Keberhasilan Pengobatan & 0.813341 & Valid \\
\hline & KPO23 <- Keberhasilan Pengobatan & 0.83206 & Valid \\
\hline & KPP $1<-$ KPP Perawat & 0.820395 & Valid \\
\hline & KPP17 <- KPP Perawat & 0.702361 & Valid \\
\hline & KPP2 <- KPP Perawat & 0.81901 & Valid \\
\hline & KPP3 <- KPP Perawat & 0.84814 & Valid \\
\hline & KpD7 <- KPP Dokter & 0.860226 & Valid \\
\hline & Y1 <- Kepuasan Pasien & 0.798654 & Valid \\
\hline & Y2 <- Kepuasan Pasien & 0.839209 & Valid \\
\hline & Y3 <- Kepuasan Pasien & 0.66856 & Valid \\
\hline \multirow{6}{*}{$\begin{array}{c}\text { Average Variance } \\
\text { Extracted (AVE) }\end{array}$} & KPP Dokter & 0.727983 & Valid \\
\hline & KPP Farmasi & 0.644657 & Valid \\
\hline & KPP Perawat & 0.639119 & Valid \\
\hline & Keberhasilan Pengobatan & 0.66123 & Valid \\
\hline & Kemudahan Admin & 0.598263 & Valid \\
\hline & Kepuasan Pasien & 0.596364 & Valid \\
\hline \multirow{6}{*}{ Composite Reliability } & KPP Dokter & 0.929721 & Reliabel \\
\hline & KPP Farmasi & 0.87869 & Reliabel \\
\hline & KPP Perawat & 0.875762 & Reliabel \\
\hline & Keberhasilan Pengobatan & 0.906888 & Reliabel \\
\hline & Kemudahan Admin & 0.881093 & Reliabel \\
\hline & Kepuasan Pasien & 0.814577 & Reliabel \\
\hline
\end{tabular}

Sumber: Hasil Output SmartPLS 
Gambar 3

Hasil Algoritma PLS

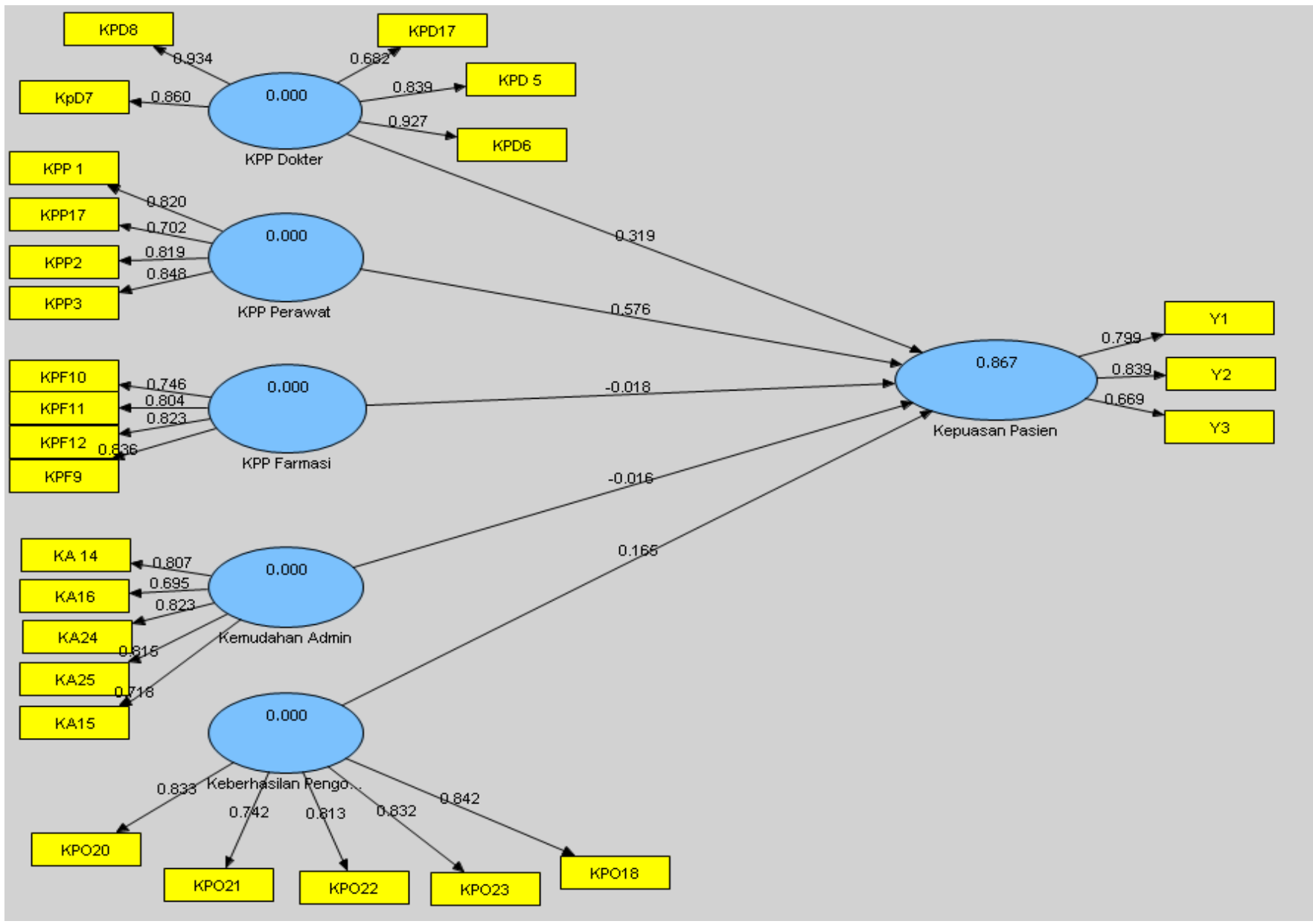

Sumber: Hasil Output SmartPLS

Tabel 3

Hasil Inner Model T-Statistic

\begin{tabular}{|l|r|l|}
\hline Variabel Dependen & Tingkat Signifikasi & Hasil \\
\hline KPP Dokter & 3.735511 & Signifikan \\
\hline KPP Farmasi & 0.342556 & Tidak Signifikan \\
\hline KPP Perawat & 8.381293 & Signifikan \\
\hline Keberhasilan Pengobatan & 2.16899 & Signifikan \\
\hline Kemudahan Admin & 0.204306 & Tidak Signifikan \\
\hline
\end{tabular}

Sumber: Hasil Output SmartPLS 